\title{
Accuracy of immunoblotting assay for detection of specific IgE compared with ImmunoCAP in allergic patients
}

Raheleh Shokouhi Shoormasti ${ }^{1}$, Mohammad Reza Fazlollahi ${ }^{2}$, Anoshirvan Kazemnejad ${ }^{3}$, Masoud Movahedi ${ }^{4}$, Behnoosh Tayebi ${ }^{1}$,Zahra Yazdanyar ${ }^{5}$, Zakieh Azadi $^{5}$, Zahra Pourpak ${ }^{6}$, Mostafa Moin ${ }^{7}$

${ }^{1}$ Ph.D. Student, Immunology, Asthma and Allergy Research Institute, Tehran University of Medical Sciences, Tehran, Iran

${ }^{2}$ MD., Allergist and Clinical Immunologist, Assistant Professor, Immunology, Asthma and Allergy Research Institute, Tehran University of Medical Sciences, Tehran, Iran

${ }^{3}$ Ph.D. of Biostatistics, Professor, Department of Biostatistics, Faculty of Medical Sciences, Tarbiat Modares University, Tehran, Iran

${ }^{4}$ MD., Allergist and Clinical Immunologist, Professor, Department of Allergy and Clinical Immunology, Children Medical Center, Tehran University of Medical Sciences, Tehran, Iran

${ }^{5}$ B.Sc., Immunology, Asthma and Allergy Research Institute, Tehran University of Medical Sciences, Tehran, Iran

${ }^{6} \mathrm{MD}$, Ph.D. of Immunology, Professor, Immunology, Asthma and Allergy Research Institute, Tehran University of Medical Sciences, Tehran, Iran

${ }^{7}$ MD., Allergist and Clinical Immunologist, Professor, Immunology, Asthma and Allergy Research Institute, Tehran University of Medical Sciences, Tehran, Iran

\section{Type of article: Original}

\begin{abstract}
Background and aim: Standardized techniques help us to better diagnosis and follow up of allergic diseases. In this study, we determined the sensitivity, accuracy, and specificity of an Immunoblotting test compared to ImmunoCAP as the reference in vitro test for detection of specific IgE in allergic patients.

Methods: In this cross-sectional study, specific IgE level was determined in patients with allergic symptoms who referred to the Immunology, Asthma and Allergy Research Institute, Tehran, Iran from 2010-2016, by two techniques. Eleven different allergens (six aeroallergens and five food allergens) were determined, and 303 specific IgE tests were performed for the patients by each method. The Immunoblotting test is a multiplex assay on a nitrocellulose membrane coated with 20 selected allergens. ImmunoCAP is considered as the reference method for determination of in vitro specific IgE. Its principle is an automated sandwich immunoassay, and allergens were bound to the solid phase, covalently. Finally, the fluorescence of elute was determined. Specific IgE more than $0.35 \mathrm{KU} / \mathrm{L}$ was considered as a positive test. Sensitivity, specificity, accuracy, kappa coefficient, positive and negative likelihood ratio (+/- LR), and correlation coefficient (calculated with Spearman test) between two tests were determined using statistical analysis (SPSS software, version 18).

Results: One hundred and thirty five patients entered this study. The median age of the patients was 3.75 years with the males constituting $54.8 \%$ of the population. The most common cheif complaints were respiratory (51.6\%), skin (41.8\%) and gastrointestinal $(27.9 \%)$ symptoms, respectively. The sensitivity, specificity, accuracy, + LR and -LR were $83 \%, 97 \%, 92 \%, 27.66$ and 0.17 , respectively. The kappa coefficient of the immunoblotting test was 0.81 compared to the reference technique. The correlation coefficient for positive tests between the two methods was $0.71(\mathrm{p}<0.001)$.
\end{abstract}

Conclusion: Regarding the presence of 20 allergens in a RIDA allergy panel and according to our findings, this

\section{Corresponding author:}

Professor Dr. Zahra Pourpak. Immunology, Asthma and Allergy Research Institute, Tehran University of Medical Sciences. P.O.BOX:14185-863, Tehran, IR. Iran.

Tel: +98.2166919587, Fax:+98.216642899, E-mail: pourpakz@sina.tums.ac.ir

Received: August 06, 2017, Accepted: November 25, 2017, Published: February 2018

iThenticate screening: August 26, 2017, English editing: December 02, 2017, Quality control: January 04, 2018

This article has been reviewed / commented by four experts

(C) 2018 The Authors. This is an open access article under the terms of the Creative Commons Attribution-NonCommercialNoDerivs License, which permits use and distribution in any medium, provided the original work is properly cited, the use is non-commercial and no modifications or adaptations are made. 
immunoblotting test with high sensitivity could be used as a fast and cost-efficient screening test. However, ImmunoCAP is recommended when the accurate level of specific IgE is required. ImmunoCAP findings are particularly helpful for immunotherapy and the elimination diet.

Keywords: Sensitivity, Specificity, Immunoblotting, Specific IgE

\section{Introduction}

Allergen-specific IgE is commonly used as an indicator of allergic diseases, and helps physicians for better diagnosis and treatment of allergic patients (1). Although the development of allergenic molecules and microarray technique have resulted in a comprehensive evaluation of $\mathrm{IgE}$ profile and determination of cross-reactive proteins, allergenic extracts are still the fundamental screening tools that cannot be excluded from diagnosis tests, as physicians apply them in the initial steps of patients work-up (2). Accurate diagnosis and effective treatment are obtained using clinical history, physical examination and a precise laboratory evaluation (3). An ideal test should have high accuracy and reliability (4). There are several in vivo and in vitro tests for exact identification of allergens developing allergic diseases. Skin prick test (SPT) (in vivo) and specific IgE measurement (in vitro) are the most common used methods (5). SPT is a cheaper and a higher sensitive technique compared to in vitro tests. However, some of its disadvantages have resulted in widespread application of in vitro tests. Some disadvantages of SPT include lower specificity, invasiveness, and inability to sample storage. In addition, patients suffering from dermographism, severe asthma, urticaria, eczema or anaphylactic reaction, and those taking specific medications may not be good candidates for SPT (6-8). There are two different in vitro methods for evaluating specific IgE against one allergen and simultaneous multiple allergens, including singleplex platform (such as ImmunoCAP system) and multiplex platform (such as RIDA allergy screen) (9). The mechanism of most common systems (such as ImmunoCAP, Immunlite (Siemens) and Hytec-288 (Hycor) is similar to the radioallergosorbent test. In these techniques, IgE calibration curve is used (10). ImmunoCAP is a precise technique from the second generation of in vitro tests for evaluating allergen-specific IgE with ideal reliability, reproducibility, and good matching with SPT results (11). Although it has been accepted as an exact method for detection of specific IgE, it is an expensive test $(5,11)$. RIDA qline Allergy test (R-Biopharm, Darmstadt, Germany), MAST optigen (Hitachi Chemical diagnostic) and Polycheck Allergy (Biocheck $\mathrm{GmbH}$ ) are the most famous types of multiplex assay (11). They can detect the specific IgE for multiple allergens with lower cost (12). Although this comparison was performed in previous studies $(11,13)$, contradiction existed in their results. Considering the fact that we were planning for a populationbased screening study, it was necessary to repeat this comparison in our laboratory to draw more firm conclusions. Difficult availability to reagents of ImmunoCAP system in our country and the cost of this modality led us to utilize alternative available methods to detect the specific IgE. It is worth mentioning that as a referral center, we prefer to apply screening tests with the lowest possible prices, and use more expensive specialized evaluations for selected patients. The advantages of this immunoblotting method (RIDA allergy Screen) such as its availability, independence of high technology instruments, availability of different standard panels, possibility of customizing a specific panel for each region, economical price, and lower serum sample (14) led us to determine the sensitivity and specificity of this test compared with ImmunoCAP as a reference method (5) with its high accuracy for detection of specific IgE in allergic patients.

\section{Material and Methods}

Patients with allergic symptoms including respiratory symptoms (wheezing, breathlessness, rhinitis), skin symptoms (eczema and urticaria), and gastrointestinal symptoms (diarrhea, vomiting, blood in stool) related to foods and aeroallergens referred to the Immunology, Asthma, and Allergy Research Institute (IAARI), Tehran University of Medical Sciences, Tehran, Iran were included from 2010 to 2016. The subjects without clear history of these symptoms were excluded from this study. This cross-sectional study was approved by the Ethics Committee of IAARI (412/P/326). Five $\mathrm{mL}$ of blood was taken from all patients after obtaining informed consent. Their serum was separated and stored at $-70{ }^{\circ} \mathrm{C}$. Two different panels of immunoblot assay (Pediatric and local inhalant panels) were used. Each panel includes 20 different allergens. Molds and house dust mite allergens were used as mites mix and mold mix in this immunoblot assay and ImmunoCAP. The used allergens as mix include the same allergens in both different methods. All samples were checked for six aeroallergens (Bermuda grass, mite mix, mold mix, mugwort, dermatophagoides pteronyssinus and dermatophagoides farina) and five food allergens (egg white, egg yolk, cow's milk, wheat, and soybean) by two methods. The list of used allergens in each technique is shown in Table 1. Immunoblotting test (RIDA Allergy Screen or RIDA qline Allergy, R-Biopharm, Darmstadt, Germany) is an enzyme immunoassay on nitrocellulose membrane to determine specific IgE to 20 selected aeroallergens and food allergens on each strip. After washing the strips with washing buffer, serum samples (250-400 $\mu 1$ for RIDA Allergy Screen and RIDA qline Allergy, respectively) were added to each allergen-coated membrane. This sample 
volume is used to detect specific IgE to 20 allergens. Then, membranes were incubated on a shaker at room temperature (RT). After washing, biotin-conjugated anti-IgE was poured on each strip. In the next step, following incubating and washing, streptavidin conjugated with alkaline phosphatase was added to the strip. Then, incubation and washing phase was performed. In the final step, BCIP/NBT (bromochloroindolyl phosphate / Nitro blue tetrazolium) was poured into each membrane. Quantification of specific IgE was done using a scanner and specific software. The values are reported as IU $/ \mathrm{ml}$ unit. Specific IgE $>0.35 \mathrm{IU} / \mathrm{ml}$ was considered as positive. ImmunoCAP (Thermo Fisher Scientific, Uppsala, Sweden) is a solid phase immunoassay. The solid phase is a capsule including cellulose derivative with high binding capacity. The detection of specific IgE by ImmunoCAP system was performed according to the manufacture's instruction. Forty $\mu 1$ of serum samples were used for measurement of specific IgE for each allergen. This process lasts about three hours. Data were analyzed by SPSS software version 18 (SPSS Inc., Chicago, USA). To determine the normality of quantitative variables, Kolmogorov-Smirnov was used. The sensitivity, specificity, accuracy, positive predictive value, negative predictive value, positive and negative likelihood ratios, and kappa coefficient were calculated. ImmunoCAP test was considered as the gold standard method. The Spearman test was used for evaluation of the correlation between the two methods. P value less than 0.05 was considered as significant level.

Table 1. The list of used allergens in ImmunoCAP and RIDA Allergy Screen test

\begin{tabular}{|l|l|l|l|l|l|}
\hline ImmunoCAP Allergens & Code & RIDA Allergens & Code & RIDA Allergens & Code \\
\hline Inhalant Allergens & & Panel IAARI & & Panel (Pediatric) & \\
\hline Bermuda grass & G2 & Acacia & T36 & D. pteronyssinus & D1 \\
\hline Mugwort & W6 & Ash & T15 & D. farinae & D2 \\
\hline Mite Mix & HX2 & Elder & T26 & Grass Mix & Gx1 \\
\hline Mold Mix & MX1 & Elm & T8 & Birch & T3 \\
\hline D. pteronyssinus & D1 & Plane tree & T11 & Cat & E1 \\
\hline D. farinae & D2 & Cypress & T23 & Dog & E5 \\
\hline Food Allergens & & Scot pine & T16 & Alternaria & M6 \\
\hline Cow's milk Protein & F2 & Poplar & T14 & Milk & F2 \\
\hline Egg White & F1 & Rye & G5 & $\alpha$ lactalbumin & F72 \\
\hline Egg Yolk & F75 & Timothy grass & G6 & $\beta$ Lactoglobulin & F76 \\
\hline Wheat Flour & F4 & Bermuda grass & G2 & casein & F77 \\
\hline Soy bean & F14 & Goosefoot & W10 & Bovine serum Albumin & F78 \\
\hline & & Saltwort & W11 & Egg White & F1 \\
\hline & & Mugwort & W6 & Egg Yolk & F75 \\
\hline & & Mite Mix & DX1 & Carrot & F31 \\
\hline & & Mold & Mx1 & Potato & F35 \\
\hline & & Feather & Ex6 & Soy bean & F14 \\
\hline & & Cockroach & I6 & Wheat Flour & F4 \\
\hline & & Dog & E5 & Peanut & F13 \\
\hline & Cat & E1 & Hazelnut & F17 \\
\hline
\end{tabular}

\section{Results}

Totally, 135 patients (54.8\% Male, 45.2\% Female) were tested for 11 different allergens. The median age of patients was $3.75(\mathrm{Q} 1, \mathrm{Q} 3=1,11)$ years. The chief complaints of patients were respiratory $(51.6 \%)$, skin $(41.8 \%)$ and gastrointestinal symptoms (27.9\%), respectively. Three hundred and three tests ( 88 aeroallergens, 215 food allergens tests) were performed with the two methods, simultaneously. The sensitivity and specificity were $83 \%$ and $97 \%$, respectively. Positive likelihood ratio (+LR) and negative likelihood ratio (-LR) are 27.66 and 0.17 , respectively. The Immunoblotting assay showed substantial agreement (kappa coefficient $=0.81$ ) compared with ImmunoCAP. The accuracy of this test is $92 \%$ compared with the reference $\operatorname{IgE}$ in vitro test (ImmunoCAP). The correlation coefficient between the two methods was calculated with Spearman test (correlation coefficient $=0.71, \mathrm{p}<0.001$ ) (Figure 1). Table 2 shows the sensitivity, specificity, and agreement between the two methods in aeroallergens and food allergens, independently. The sensitivity of the the RIDA Allergy assay was better for specific IgE to aeroallergens $(89.3 \%)$ compared to specific IgE for food allergens $(81 \%)$, while the specificity of specific IgE for food allergens (98\%) was better in comparison with specific IgE for aeroallergens (93\%). The number of positive and negative tests, sensitivity, specificity, PPV, NPV and agreement of this immunoblotting test in comparison with ImmunoCAP for each particular allergen, has been shown in Table 3. 
http://www.ephysician.ir

Table 2. The sensitivity, specificity, positive predictive value (PPV), negative predictive value (NPV), agreement and kappa value in two methods

\begin{tabular}{|c|c|c|c|c|c|c|c|c|c|c|c|}
\hline \multirow[t]{2}{*}{ Allergens } & \multirow{2}{*}{$\begin{array}{l}\text { Total } \\
\text { Number } \\
\text { of tests }\end{array}$} & \multicolumn{2}{|c|}{$\begin{array}{l}\text { Number of positive } \\
\text { tests }\end{array}$} & \multirow[t]{2}{*}{$\begin{array}{l}\text { Sensitivity, } \\
\%\end{array}$} & \multirow[t]{2}{*}{$\begin{array}{l}\text { Specificity, } \\
\%\end{array}$} & \multirow[t]{2}{*}{$\begin{array}{l}\mathrm{PPV}, \\
\%\end{array}$} & \multirow[t]{2}{*}{$\begin{array}{l}\mathrm{NPV}, \\
\%\end{array}$} & \multirow[t]{2}{*}{$\begin{array}{l}\text { Agreement, } \\
\%\end{array}$} & \multirow[t]{2}{*}{ Kappa } & \multirow[t]{2}{*}{$\begin{array}{l}\mathrm{p}- \\
\text { value }\end{array}$} & \multirow[t]{2}{*}{ SE } \\
\hline & & RIDA & ImmunoCAP & & & & & & & & \\
\hline Aeroallergens & 88 & 29 & 28 & 89.3 & 93 & 86 & 95 & 92 & 0.82 & $<0.001$ & 0.06 \\
\hline $\begin{array}{l}\text { Food } \\
\text { Allergens } \\
\end{array}$ & 215 & 71 & 85 & 81 & 98 & 97 & 89 & 92 & 0.82 & $<0.001$ & 0.04 \\
\hline Total & 303 & 100 & 113 & 83 & 97 & 94 & 91 & 92 & 0.81 & $<0.001$ & 0.03 \\
\hline
\end{tabular}

Table 3. The sensitivity, specificity, PPV, NPV and Kappa value of immunoblotting assay (RIDA Allergy Screen) compared

\begin{tabular}{|c|c|c|c|c|c|c|c|c|c|}
\hline \multirow[t]{2}{*}{ Allergens } & \multirow[t]{2}{*}{$\mathrm{n}$} & ImmunoCAP & $\begin{array}{l}\text { Immunoblotting } \\
\text { Assay }\end{array}$ & \multirow[t]{2}{*}{$\begin{array}{l}\text { Sensitivity, } \\
\%\end{array}$} & \multirow[t]{2}{*}{ Specificity,\% } & \multirow[t]{2}{*}{$\begin{array}{l}\mathrm{PPV}, \\
\%\end{array}$} & \multirow[t]{2}{*}{$\begin{array}{l}\text { NPV, } \\
\%\end{array}$} & \multirow[t]{2}{*}{$\begin{array}{l}\text { Kappa } \\
\text { value }\end{array}$} & \multirow[t]{2}{*}{$\begin{array}{l}\mathrm{p}- \\
\text { value }\end{array}$} \\
\hline & & $\begin{array}{l}\text { Number of } \\
\text { Positive } \\
\text { Tests }\end{array}$ & $\begin{array}{l}\text { Number of } \\
\text { Positive } \\
\text { Tests }\end{array}$ & & & & & & \\
\hline Bermuda grass & 16 & 7 & 7 & 86 & 89 & 86 & 89 & 0.75 & 0.003 \\
\hline Mugwort & 15 & 6 & 5 & 83.3 & 100 & 100 & 90 & 0.86 & 0.001 \\
\hline Mite Mix & 11 & 3 & 4 & 100 & 88 & 75 & 100 & 0.79 & 0.007 \\
\hline Mold Mix & 16 & 2 & 4 & 100 & 86 & 50 & 100 & 0.60 & 0.009 \\
\hline $\begin{array}{l}\text { Dermatophagoides } \\
\text { Pteronyssinus }\end{array}$ & 16 & 6 & 6 & 100 & 100 & 100 & 100 & 1.00 & $<0.001$ \\
\hline $\begin{array}{l}\text { Dermatophagoides } \\
\text { farinae }\end{array}$ & 14 & 4 & 3 & 75 & 100 & 100 & 91 & 0.81 & 0.002 \\
\hline Cow's milk & 65 & 34 & 32 & 91 & 97 & 97 & 91 & 0.88 & $<0.001$ \\
\hline Egg White & 49 & 16 & 11 & 69 & 100 & 100 & 87 & 0.75 & $<0.001$ \\
\hline Egg Yolk & 37 & 8 & 2 & 25 & 100 & 100 & 83 & 0.34 & 0.006 \\
\hline Wheat Flour & 55 & 27 & 26 & 93 & 96 & 96 & 93 & 0.89 & $<0.001$ \\
\hline Soy bean & 9 & 0 & 0 & NA & 100 & NA & NA & NA & - \\
\hline
\end{tabular}

NA: Not Available

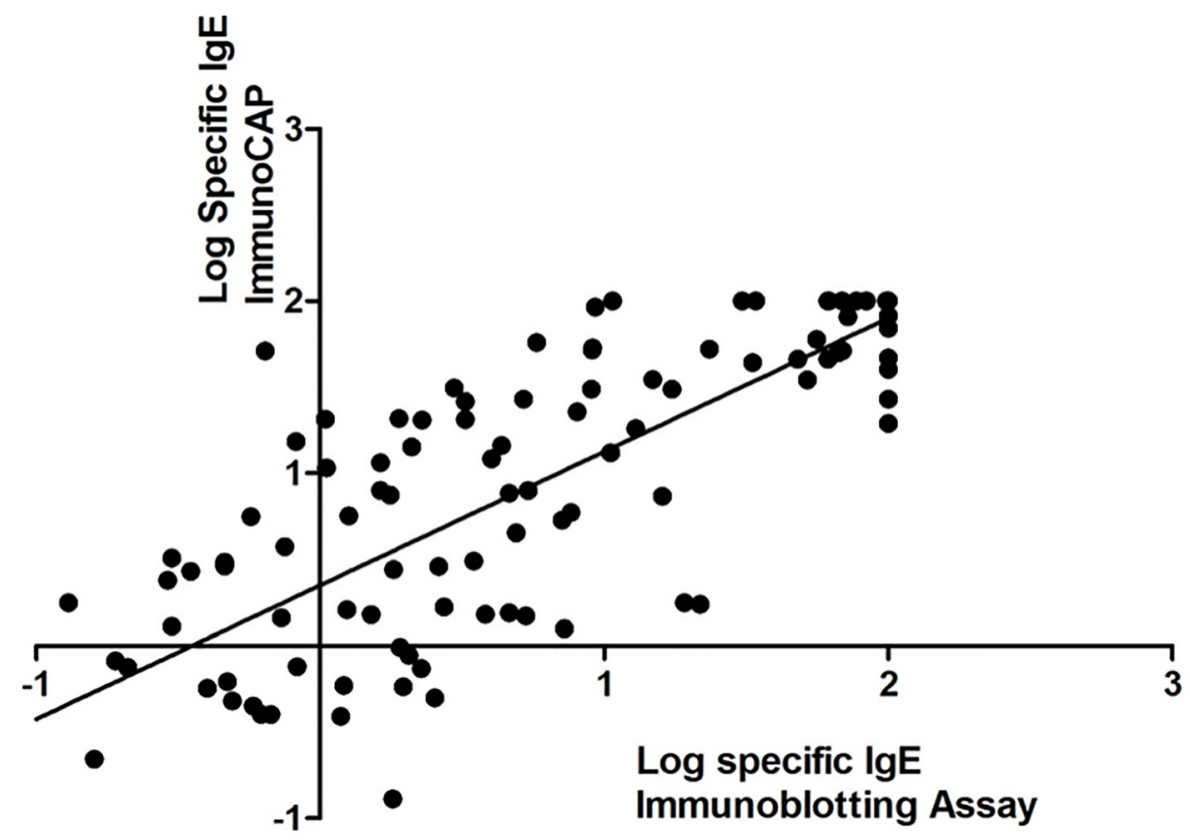

Figure 1. The scatter plot of correlation between $\log$ specific IgE in both methods 


\section{Discussion}

Comparison of specific IgE against 11 allergens with two methods showed good sensitivity (83\%) and specificity (97\%) for the immunoblotting assay compared with ImmunoCAP. This study showed the good agreement (92\%) between the two methods for evaluating the specific IgE. Detection of the sensitizer allergen with a precise and reliable assay is important in allergic patients (3). According to our findings, the accuracy of immunoblot assay for food and aeroallergens was somehow similar to ImmunoCAP method. Our results are inconsistent with the results of Minje Han for agreement between the two assays. In their study, agreement percentage between the two methods was better for aeroallergens than food allergens (53.8\% versus 40.9\%) (11). In the study of Eun-Jee Oh et al. (13), the agreement $(29.1 \%)$ among these two methods was surprisingly much less than our study $(92 \%)$. The used source and feature of allergenic extract could be one of the major reasons for the difference between these techniques. The results of IgE assays are greatly affected by the content and amount of allergen extract (2, 15). The technical discrepancy and use of different species of an allergen are the reasons of different levels of allergen-specific IgE in types of commercial assays (1). The sensitivity, specificity, and concordance of two methods are different among different allergens. Regarding this study's results, dermatophagoides Pteronyssinus, wheat flour and cow's milk allergens showed the highest agreement between the two methods. The lowest agreement was found in terms of sensitization to egg yolk. Comparing these two techniques, in the study of Eun-Jee Oh, higher agreement was found for some allergens such as dermatophagoides Pteronyssinus and wheat flour; while other allergens such as milk did not show such agreement between two methods (13). AlloScreen and RIDA Allergy Screen test as two immunoenzyme assays on nitrocellulose membrane have similar principles. In a study by Park et al., the agreement between the two methods (Immunoblotting and ImmunoCAP) ranged from 0.74 to 0.93 . In this study, similar results were obtained (16). This multiplex assay is simple with appropriate and acceptable cost compared with ImmunoCAP (12). In our study, the sensitivity and specificity compared to the immunoblot assay is somewhat similar to the Park study in Korea (sensitivity $=74.4 \%$, specificity $=85.5 \%$ ) (12). In spite of the difference between selective allergens and also the race of the participants in several studies, designing of these methods to measure specific IgE is free from any confounding factors. The sensitivity of RIDA Allergy test regarding different inhalant and food allergens had ranged from $75-100 \%$ and $25-93 \%$, respectively. On the other hand, specificity of this test in comparison with ImmunoCAP was between 86 to 100\% and 96 to $100 \%$, respectively. Regarding these findings, it seems that sensitivity of this test for aeroallergens is better compared with food allergens. The prolongation of this study due to an attempt to increase the sample size and to analyze accurately, are the limitations of this study. Although all tests were performed accurately and with enough sample size, the performance of tests with more sample size for each individual allergen was ideal for us.

\section{Conclusions}

According to our findings, the immunoblot multiplex assay has a priority in early screening tests because of its price and also the lower volume of serum sample that is used. It is recommended to use more quantitative tests in patients who are in the procedure of treatment to evaluate the effect of the medication. The improvement of sensitivity and specificity in multiple allergen tests is important for the wide use of these panels. Also, determining the diagnostic value of this test for important allergens such as drugs and allergenic molecules is very important in future studies.

\section{Acknowledgments:}

This study was supported by the Immunology, Asthma and Allergy Research Institute, Tehran University of Medical Sciences, Tehran, Iran. The authors wish to extend special thanks to Dr. Laleh Nikfarjam, Mrs. Zahra Ebadi and Mrs. Zahra Lebaschi for their outstanding collaboration. We appreciate Dr. Shahrooei and the Department of Laboratory Medicine, University Hospitals Leuven, Leuven, Belgium for performing 50 ImmunoCAP tests.

\section{Conflict of Interest:}

There is no conflict of interest to be declared.

\section{Authors' contributions:}

All authors contributed to this project and article. All authors read and approved the final manuscript.

\section{References:}

1) Wang J, Godbold JH, Sampson HA. Correlation of serum allergy (IgE) tests performed by different assay systems. J Allergy Clin Immunol. 2008; 121: 1219-24. doi: 10.1016/j.jaci.2007.12.1150. PMID: 18243289. 
2) Matricardi PM, Kleine-Tebbe J, Hoffmann HJ, Valenta R, Hilger C, Hofmaier S, et al. EAACI Molecular Allergology User's Guide. Pediatr Allergy Immunol. 2016; 27 Suppl 23: 1-250. doi: 10.1111/pai.12563. PMID: 27288833.

3) Williams PB, Barnes JH, Szeinbach SL, Sullivan TJ. Analytic precision and accuracy of commercial immunoassays for specific IgE: establishing a standard. J Allergy Clin Immunol. 2000; 105: 1221-30. doi: 10.1067/mai.2000.105219. PMID: 10856158.

4) Szeinbach SL, Barnes JH, Sullivan TJ, Williams PB. Precision and accuracy of commercial laboratories' ability to classify positive and/or negative allergen-specific IgE results. Ann Allergy Asthma Immunol. 2001; 86: 373-81. doi: 10.1016/S1081-1206(10)62481-7. PMID: 11345278.

5) Hwang H, Kwon J, Kim JY, Lee HH, Oh CE, Choi GS. The RIDA Allergy Screen Versus the Phadiatop Test in 430 Consecutive Patient Specimens. Lab Med. 2016; 47(1): 20-9. doi: 10.1093/labmed/lmv002. PMID: 26732778.

6) Chong Neto HJ, Rosario NA. Studying specific IgE: in vivo or in vitro. Allergol Immunopathol (Madr). 2009; 37(1): 31-5. doi: 10.1016/S0301-0546(09)70249-6. PMID: 19268059.

7) Cox L, Williams B, Sicherer S, Oppenheimer J, Sher L, Hamilton R, et al. Pearls and pitfalls of allergy diagnostic testing: report from the American College of Allergy, Asthma and Immunology/American Academy of Allergy, Asthma and Immunology Specific IgE Test Task Force. Ann Allergy Asthma Immunol. 2008; 101(6): 580-92. doi: 10.1016/S1081-1206(10)60220-7. PMID: 19119701.

8) Heinzerling L, Mari A, Bergmann KC, Bresciani M, Burbach G, Darsow U, et al. The skin prick test European standards. Clin Transl Allergy. 2013; 3(1): 3. doi: 10.1186/2045-7022-3-3. PMID: 23369181.

9) Ihm YK, Kang SY, Kim MH, Lee WI. Chemiluminescent Assay Versus Immunoblotting for Detection of Positive Reaction to Allergens. Labmedicine. 2012; 43: 91-5. doi: 10.1309/LMK23OPMAVHH3XTI.

10) Goikoetxea MJ, Sanz ML, Garcia BE, Mayorga C, Longo N, Gamboa PM, et al. Recommendations for the use of in vitro methods to detect specific immunoglobulin E: are they comparable? J Investig Allergol Clin Immunol. 2013; 23: 448-54. PMID: 24654308.

11) Han M, Shin S, Park H, Park KU, Park MH, Song EY. Comparison of three multiple allergen simultaneous tests: RIDA allergy screen, MAST optigen, and polycheck allergy. Biomed Res Int. 2013; 2013: 340513. doi: 10.1155/2013/340513. PMID: 23484110.

12) Park DS, Cho JH, Lee KE, Ko S, Kim HR, Choi SI, et al. Detection rate of allergen-specific IgE by multiple antigen simultaneous test-immunoblot assay. Korean J Lab Med. 2004; 24: 131-8.

13) Oh EJ, Lee SA, Lim J, Park YJ, Han K, Kim Y. Detection of allergen specific IgE by AdvanSure Allergy Screen test. Korean J Lab Med. 2010; 30(4):420-31. doi: 10.3343/kjlm.2010.30.4.420. PMID: 20805716.

14) Derived from; https://clinical.r-biopharm.com/products/rida-qline-allergy-panel-2-3-1/.

15) Hamilton RG. Clinical laboratories worldwide need to report IgE antibody results on clinical specimens as analytical results and not use differential positive thresholds. J Allergy Clin Immunol. 2015; 136: 811-2. doi: 10.1016/j.jaci.2015.03.002. PMID: 25863980.

16) Park KH, Lee J, Lee SC, Son YW, Sim DW, Lee JH, et al. Comparison of the ImmunoCAP Assay and AdvanSure $^{\mathrm{TM}}$ AlloScreen Advanced Multiplex SpecificIgE Detection Assay. Yonsei Med J. 2017; 58(4): 786-92. doi: 10.3349/ymj.2017.58.4.786. PMID: 28540992, PMCID: PMC5447110. 